\title{
Imaginario y simbología del agua en seis poemas de temática clásica de Jorge Luis Borges
}

\author{
Imaginary and symbology of water in six classical themed poems \\ by Jorge Luis Borges
}

\author{
Minor Herrera Valenciano \\ Sede de Occidente \\ Universidad de Costa Rica, Costa Rica
}

\section{Resumen}

El simbolismo del agua y la construcción de un imaginario en torno a esta constituyen una de las manifestaciones literarias más extensamente tratada por los autores latinoamericanos del Boom, pues este elemento teje una serie de relaciones intrincadas en las que se junta el mundo metafísico con el mundo físico; la consciencia con el inconsciente colectivo; la razón y la pasión.

Este artículo muestra cómo el agua ocupa una posición esencial en algunos poemas de tema clásico (grecolatino) escritos por Jorge Luis Borges para desarrollar ideas como el olvido, la muerte, el tiempo y la discontinuidad, ya presentes en los imaginarios griego y romano (conocidos muy bien por el autor), y tan recurrentes en relatos épicos. Para tal fin, se analizarán los poemas titulados "Proteo", "Brunanburh", "En memoria de Angélica", "Al espejo", "Efialtes", publicados en el poemario titulado La rosa profunda (1975) y "Heráclito", publicado en el poemario La Moneda de Hierro (1976).

Palabras clave: poesía, símbolo, imaginario, agua, Jorge Luis Borges

\begin{abstract}
The symbolism of water and the construction of an imaginary around it constitute one of the literary manifestations most extensively treated by the Latin American authors of the Boom, since this element weaves a series of intricate relationships in which the metaphysical world meets the physical world ; consciousness with the collective unconscious, reason and passion.
\end{abstract}


This article shows how water occupies an essential position in some classic poems (Greco-Latin) written by Jorge Luis Borges to develop ideas such as forgetting, death, time and discontinuity, already present in the Greek and Roman imaginaries (well known by the author), and so recurrent in epics stories. For this purpose, the poems entitled Proteo, Brunanburh, En memoria de Angelica, Al espejo, Efialtes, published in the poetry book entitled La rosa profunda (1975) and Heráclito, published in the collection La Moneda de Hierro (1976), will be analyzed.

Keywords: poetry, symbol, Imaginary, Water, Jorge Luis Borges

\section{Introducción}

$\mathrm{E}$ l simbolismo del agua y el imaginario surgido en torno a esta constituyen una de las manifestaciones literarias más extensamente explotadas por los autores latinoamericanos del Boom. Este elemento teje una serie de relaciones intrincadas en las que se junta el mundo metafísico con el mundo físico; la consciencia con el inconsciente colectivo; la razón y la pasión.

Unido a lo anterior, será necesario partir de la teoría del imaginaire (imaginario), ya que esta constituye una herramienta esencial cuando se pretende abordar una época y la manera en que los individuos comprenden las situaciones de la vida a las que solamente se puede ofrecer explicaciones relacionadas con lo mítico-simbólico, como la muerte, los sueños, el destino del alma, el tiempo, elementos con los que el agua ha sido típicamente relacionada.

El concepto del 'imaginario' es bastante reciente, prácticamente es introducido a la academia durante la segunda mitad del siglo XX, desde Francia, país en el que fue concebido (imaginaire) y donde se ha desarrollado profusamente.
Lo interesante del imaginaire es que permite valerse de la interdisciplinariedad para realizar las exégesis, es decir, que condensa conceptos y perspectivas de análisis distintas con el fin de posibilitar, en el campo de la literatura, una explicación hermenéutica del texto en cuestión. De ese modo, dicha teoría permite el análisis textual desde múltiples puntos de vista, por ejemplo, el filosófico, histórico, psicológico, filológico, religioso, antropológico $\mathrm{y}$, como se verá en este trabajo, mítico y simbólico.

De este modo, el presente artículo muestra cómo el agua ocupa una posición esencial en algunos poemas de tema clásico escritos por Jorge Luis Borges para desarrollar ideas como el olvido, la muerte, el tiempo y la discontinuidad, ya presentes en los imaginarios griego y romano (conocidos muy bien por el autor), y tan recurrentes en relatos épicos. Para tal fin se analizarán los poemas titulados "Proteo", "Brunanburh", "En memoria de Angélica", "Al espejo" y "Efialtes", publicados en el poemario $L a$ rosa profunda (1975), y "Heráclito", publicado en el poemario La Moneda de Hierro (1976). 


\section{L'imaginaire: acercamiento teórico}

El primero en desarrollar dicha teoría ampliamente fue Gilbert Durand (2004), quien, siguiendo los estudios de su maestro Gastón Bachelard, elabora su tesis doctoral llamada Las estructuras antropológicas del imaginario. Introducción a la arquetipología, en dicha obra el imaginario es definido como "conjunto de imágenes y las relaciones de imágenes que constituyen el capital pensante del homosapiens" (p. 21). Este concepto por sí mismo permite reconocer el valor de las imágenes (principalmente metáforas o estructuras que se repiten numerosas veces en un texto) como elementos con una enorme carga simbólica y que poseen mucha importancia, pues el significado que encierran refleja el pensamiento de los individuos de una determinada época.

Posteriormente, en su obra Lo imaginario (2000), se apoya en los estudios realizados por J. J. Wunenburger y amplía más la definición, el sentido y la importancia que se le debe atribuir al imaginario. Él menciona que dichas imágenes y las relaciones que existen entre ellas han sido previamente organizadas por una narración claramente mítica y que funcionan como mecanismo para interpretar simbólicamente y, de este modo, abordar la vida de los individuos, de las sociedades y sus creencias, en fin, a todos los seres humanos, independientemente del momento histórico en que se ubique. Para J. J. Wunenburger, citado por Durand (2000), lo imaginario representa:

el conjunto de imágenes mentales $y$ visuales, organizadas entre ellas por el sermo mythicus, por la cual un individuo, una sociedad, de hecho la humanidad entera, organiza y expresa simbólicamente sus valores existenciales y su interpretación del mundo frente a los desafíos impuestos por el tiempo y la muerte. El imaginario [...] se convierte de este modo en una categoría antropológica, primordial y sintética, a partir de la que pueden entenderse las obras de arte, y también las representaciones racionales (por lo tanto, la ciencia misma) y a fin de cuentas el conjunto de la cultura. (pp. 9-10)

Desde la perspectiva anterior, todo el devenir del ser humano se ha apoyado en la creación de imaginarios, por medio de los que pretende dar explicaciones a lo que desconoce. Así las cosas, para el estudio del imaginario, sería necesario apoyarse en algunos conceptos o teorías importantes propias de otras disciplinas, de manera tal que el acercamiento al objeto de estudio pueda ser abordado cabalmente, sin descontextualizarlo de su momento de creación. En ese sentido, apoyarse en disciplinas como la etimología, la historia, la antropología, la religión, la filosofía y la literatura sería de gran ayuda en procura de la comprensión de una determinada sociedad y su manera de pensar y comprender el mundo que la rodea. Por tal razón, Durand (2004) menciona que "es realmente el imaginario lo que aparece como recurso supremo de la conciencia, como el corazón viviente del alma cuyas diástoles y sístoles conforman la autenticidad del cogito" (p. 436).

Lo mítico y lo simbólico, desde la teoría del imaginario, brinda un valioso aporte para la explicación de lo histórico. Esto se evidencia cuando Durand 
(1993) señala que existe una marcada continuidad entre las antiguas mitologías y los relatos culturales modernos y que incluso es posible encontrar más realidad en las narraciones míticas que en aquellos hechos vistos como verdades históricas:

Hay más en el sueño o en el deseo mítico que en el acontecimiento histórico que a menudo lo hace realidad, porque los comportamientos concretos de los hombres y precisamente el comportamiento histórico, repiten tímidamente, y con mayor o menor acierto, los decorados y las situaciones dramáticas de los grandes mitos. (p. 11)

En ese sentido, la teoría del imaginario, desde lo propuesto por Durand, pretende explicar lo "real" desde el desentrañamiento del mito y el símbolo, aunque haya que valerse de conceptos tomados de diversas disciplinas, pues, como lo menciona J. J. Wunenburger, en una entrevista realizada por Bauzá (2007): forman parte del imaginaire las concepciones precientíficas, la ciencia ficción, las creencias, las producciones artísticas, las ficciones políticas, los estereotipos, los elementos históricos, arqueológicos y los prejuicios sociales. En ese sentido, menciona "convengamos en llamar imaginaire a un conjunto de producciones mentales o materializadas en obras, sobre la base de imágenes visuales y lingüísticas (metáfora, símbolo, relato), que forman conjuntos coherentes y dinámicos que revelan una función simbólica en cuanto a un enlace de sentidos propios y figurados" (p. 220).

Unido a lo anterior, de las polivalencias de las imágenes, los mitos y los símbolos, Mircea Eliade (1989) estima que mediante la revalorización del imaginario y, con esto, del símbolo y el mito es posible revelar los más profundos aspectos de la realidad. Para él, las imágenes que evocan los textos, y principalmente aquellos que se apoyan en mitos, presuponen el inicio de la apertura del ser humano hacia lo trascendental. Asimismo, señala la importancia que posee el estudio de los símbolos para descifrar el imaginario de cada una de las civilizaciones. Además, plantea una concepción simbólica de la historia, porque el hecho muestra siempre algo que lo trasciende y es labor del exégeta, desde su campo de especialización, penetrar en las significaciones y delimitar los imaginarios, ya que "hoy comprendemos algo que en el siglo XIX ni siquiera podía presentirse: que símbolo, mito, imagen, pertenecen a la sustancia de la vida espiritual; que pueden camuflarse, mutilarse, degradarse, pero jamás extirpase" (p. 11).

Finalmente, uno de los teóricos del imaginaire más reconocidos Jöel Thomas (1992) define el imaginario como un sistema que permite la organización de las imágenes y que, de una vez, les otorga profundidad y unificación, tal como se muestra a continuación:

Es la interacción de los distintos órganos de la psique, lugar informal, dialéctica, dialógica, el complejo "discurso" entre pares antagónicos y orden / desorden adicional, racional / irracional, homogénea / heterogénea, fijo / flexible, etc. Es nuestra manera de pensar con vida. Y estas interacciones determinan una tensión organizada de las diferentes instancias de la psique, que es al mismo tiempo el motor de la evolución. (p.13) ${ }^{1}$ 
Al parecer, su definición del imaginario y los dinamismos que surgen a partir de las relaciones entre las imágenes parten del uso de dos principios esenciales, por un lado la coincidencia de los opuestos (concidentia oppositorum) y, por otro, el hecho de que cada una de las imágenes condense la estructura completa del imaginario en lo que sería una especie de metonimia de la imagen (textual o metafórica). Thomas señala que dialogando con la antigüedad es posible extraer elementos de gran utilidad para comprender el devenir de la actualidad.

Por otra parte, Bauzá (2011, p. 13) señala que los estudios del imaginaire pretenden establecer puntos de contacto entre las diversas ciencias, disciplinas, religiones y cualquier otra manifestación de lo humano con el propósito lograr conciliaciones y acuerdos. De este modo, en un mismo texto, los abordajes que se realizan bajo este amparo teórico son tantos como disciplinas existen y es posible conjuntar.

Unido a lo anterior, la teoría del imaginaire retoma y amplía la "historia de las mentalidades", entendiendo por tal el estudio de las estructuras sociales y míticas sobre las que se asienta la historia. Tal forma del saber atiende en especial a expresiones de la vida cotidiana como referente clave para la comprensión de la macro historia.

El texto literario se considera, desde esta teoría, una fuente filosófica, social, histórica y antropológica de suma importancia, ya que en sí misma integra la capacidad de enunciar las experiencias de los seres humanos y de hacerlo, desde luego, de manera mítico-simbólica.

\section{El símbolo: componente funda- mental del imaginario}

El símbolo es definido por Lotman (2002) como aquel signo cuyo significado representa cierto signo de otro plano o de otra lengua. En ese sentido, lo más común es concebir que la noción de símbolo "va unida a la idea de cierto contenido que, a su turno, sirve de plano de la expresión para otro contenido, con frecuencia de mayor valor cultural" (p. 90).

Para dicho autor, el símbolo constantemente representa uno o más textos, tanto en el plano de la expresión como en el de contenido, es decir, que siempre hay en él un carácter arcaico que permite analizar cómo era entendido en el pasado y cómo es entendido en el presente, en el cual lo más probable es que haya adquirido nuevos sentidos.

$\mathrm{Al}$ respecto, el propio Lotman (2002) señala que:

Cada cultura necesita de un estrato de textos que cumplan la función de lo arcaico... El símbolo representando un texto acabado, puede no ser incluido en una fila sintagmática y si se incluye en ella, entonces mantiene su autonomía estructural y de significado. Fácilmente se le puede desprender de su contexto semiótico y con la misma facilidad ingresa a un nuevo contexto textual. (p. 91)

Como se observa, la característica fundamental del símbolo es la resemantización. En ese sentido, el cambio constante y adaptación a nuevos contextos es lo que lo convierte en un elemento de representación cultural sumamente versátil, capaz de ajustarse 
a las circunstancias más actuales, sin perder su sentido primigenio.

Aunada con el símbolo, la imagen pasaría a conformar parte del sentido de las palabras, pues, otra de las particularidades elementales del símbolo radica en que su significado cabal no sería posible captarlo de manera directa por el pensamiento (pensamiento directo) $\mathrm{y}$, en vista de que en sí mismo contiene sentidos ligados a la presentación de imágenes, este finalmente las supera, de tal manera que le es posible reflejar lo que está ausente ante la mirada común y realidades superiores o metafísicas. Por tal razón, el símbolo se convierte en el intermediario entre lo consciente y lo inconsciente. Asimismo, Mircea Eliade (1989), en su texto Imágenes y símbolos; ensayos sobre el simbolismo mágico-religioso, manifiesta que los símbolos, junto a las imágenes con los que se asocian, conforman arquetipos colectivos y tienen su origen en la memoria popular que surge de la naturaleza social del ser humano. Además, brindan información que es sumamente difícil de transmitir a través de las palabras, tanto de manera oral como escrita; asimismo, son portadores de una realidad "sagrada y cosmológica", y su función primordial es "revelar una realidad total inaccesible a los demás medios de conocimiento" (p. 63). Por tales razones, los símbolos son plurisignificantes debido a que estos revelan varios sentidos a la vez y se constituye como un modo particularmente religioso por el cual es posible acceder a conocimientos ocultos.

En esa misma línea de pensamiento, A. Lalande (1966), citado por Durand (1968), señala que se puede definir símbolo como "todo signo concreto que evoca, por medio de una relación natural, algo ausente o imposible de percibir" (p. 13) o como lo indica Jung (2011) "la mejor representación posible de una cosa relativamente desconocida, que por consiguiente no sería posible designar en primera instancia de manera más clara o más característica" (p. 13). De esta manera, el símbolo no posee la condición de arbitrariedad y su significado no es posible de mostrar de otra manera que no sea a partir de su inmanencia. En ese sentido, el símbolo construye una especie de perímetro de significación desde el cual se erige.

Durand (1968) define símbolo como "una representación que hace aparecer un sentido secreto; es la epifanía de un misterio" (p. 15). La definición es enriquecida con los aportes de P. Ricoeur (2004), quien afirma que todo símbolo auténtico debe poseer, al menos, tres dimensiones concretas: es al mismo tiempo "cósmico", es decir, que extrae de lleno su representación del mundo visible que nos rodea; "onírico", que se arraiga en los recuerdos los gestos que aparecen en nuestros sueños; y, por último, "poético", es decir, que también recurre al lenguaje, y al lenguaje más íntimo; por lo tanto, al más concreto.

Entendido así, podría tomarse como ejemplo el agua. La imagen del agua evocará al líquido vital como elemento, mientras que el agua como símbolo evocará muchos sentidos, algunos distantes de lo que es en sí mismo dicho líquido. 


\section{La simbología del agua en seis poe- mas borgianos de temática clásica}

Proteo: el agua como símbolo de la mutabilidad

Antes que los remeros de Odisea fatigaran el mar color de vino las inasibles formas adivino de aquel dios cuyo nombre fue Proteo. Pastor de los rebaños de los mares y poseedor del don de profecía, prefería ocultar lo que sabía y entretejer oráculos dispares. Urgido por las gentes asumía la forma de un león o de una hoguera o de árbol que da sombra a la ribera o de agua que en el agua se perdía. De Proteo el egipcio no te asombres, tú, que eres uno y eres muchos hombres.

(Borges, 1989, p. 96)

Desde su más arcaica referencia, en el poema homérico de la Odisea, el dios marino, ayudante o hijo de Poseidón y ligado a la fundación del Antiguo Egipto (depende de la versión del mito que se consulte), ha adoptado, a su vez, distintas representaciones culturales; esto es, como referente de la poesía, de la alquimia, de la psicología profunda, de la profecía, esta última ligada al agua como una especie de espejo adivinatorio.

Lo primero que cabe mencionar es que, en la mitología griega, Proteo es una divinidad marina y, como es propio de la condición de estos seres de las aguas, poseía la capacidad de conocer el pasado, el presente y, lo más importante, el futuro. Entonces, se nota cómo Borges empieza enlazar un tema clásico, la adivinación, con el mar, el agua en movimiento con la continuidad del tiempo.
Ese don profético del que goza la divinidad lo convertía en un dios asediado por los mortales, quienes, no teniendo la capacidad de conocer su devenir, deseaban saber cuál sería su suerte futura. Ante el acoso de los mortales, el divino Proteo deberá ingeniárselas para permanecer oculto; eso lo lleva cambiar de forma constantemente, es decir, se torna un dios mutable.

Homero es quien primero da cuenta sobre algunos aspectos de este personaje, específicamente en el pasaje en el que Telémaco solicita información a Menelao y este le responde:

Pues yo voy, extranjero, a explicártelo todo fielmente:

suele andar por aquí cierto anciano del mar, infalible,

egipcio Proteo, inmortal que conoce los fondos

(del océano sin fin; Poseidón por vasallo tiene

y es el padre que a mí me engendró, según dicen: si fueras

tú capaz de cogerlo en celada y rendirlo a tu arbitrio,

(de tu ruta te habría de decir si será corta o larga,

y en qué modo podrás regresar sobre el mar rico en peces.(Od. IV. 383-390)

Como se observa, en estos versos, se muestra la naturaleza omnisciente y mutable de la divinidad, además de la forma en la que podría acercarse a él para obtener la tan deseada información. La naturaleza mutable de Proteo es la misma que posee el agua y la que posee la vida misma, tanto para los antiguos griegos, quienes consideraban al agua como símbolo de transformación (Jung, 2011) y la asociaban con 
los cambios repentinos de la vida, como para Jorge Luis Borges, que habiendo bebido de las fuentes del Mundo Clásico, lo acerca al ser humano y su condición voluble, cuando menciona "De Proteo el egipcio no te asombres/Tú, que eres uno y eres muchos hombres" (Borges, 1989, p. 96). En ese sentido, el primer simbolismo del agua es la mutabilidad, característica a la que se refiere cuando menciona "las inasibles formas del adivino... de agua que en el agua se perdía” (Borges, 1989, p. 96).

Cuando Borges evoca la figura de Proteo no solo se refiere a él por su divinidad y su capacidad profética sino por estar evidentemente ligado al agua, elemento que, para Bachelard, "se trata de una sustancia llena de reminiscencias y de ensoñaciones adivinatorias" (2003, p. 140). Esto recuerda la propia condición humana, que se resume en buscar en el presente respuestas de su futuro, para darle un sentido a la vida, pero que solo con el escurrimiento de las aguas del tiempo y con las experiencias vividas $\mathrm{y}$ el conocimiento apropiado se conseguirá.

Aunque esas respuestas, en ocasiones, pueden mostrarse en manifestaciones oníricas; no obstante, los sueños pueden no gustar y, contrario a lo que deseamos, pueden presentarnos situaciones aterradoras, tal como el poeta lo manifiesta en "Efialtes".

\section{Efialtes: el sueño y el agua como elemento purificador}

En el fondo del sueño están los sueños.

[Cada

noche quiero perderme en las aguas

[obscuras

que me lavan del día, pero bajo esas

[puras aguas que nos conceden la penúltima.

[Nada

late en la hora gris la obscena maravilla.

Puede ser un espejo con mi rostro

puede ser la creciente cárcel de un

[distinto,

[laberinto,

puede ser un jardín. Siempre es la

[pesadilla.

$\mathrm{Su}$ horror no es de este mundo.

Algo que no se nombra

me alcanza desde ayeres de mito y de

[neblina;

la imagen detestada perdura en la retina e infama la vigilia como infamó la

[sombra.

¿Por qué brota de mí cuando el cuerpo

[reposa

y el alma queda sola, esta insensata rosa?

(Borges, 1989, p. 113)

Nuevamente, desde el primer verso se nota el acercamiento al Mundo Clásico que Borges realiza, pues al mencionar que "En el fondo del sueño están los sueños" apunta a la conocida hermandad entre "Yпvos (Hipnos) y los 'Oveıрor (Sueños) que se comprende fácilmente en el sentido de que, sin el primero, no son posibles los segundos.

Según la tradición griega, los sueños son entes ctónicos. Homero, por ejemplo, los ubica en un espacio cercano al Hades y Hesíodo, en su teogonía, los hace descender de vuß̧ (la noche). Ahora bien, el resto de la familia se completa con personajes bastante obscuros, entre los que destaca la muerte (@ávatos). En este marco de inquietantes entes nocturnos, es lógico situar la

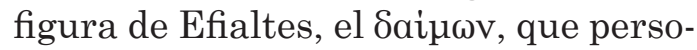
nifica la pesadilla.

Borges menciona: "Cada noche quiero perderme en las aguas obscuras 
que me lavan del día” (Borges, 1981, p. 113). Estas aguas obscuras representan el sueño, ya que según Bachelard (2003) estas "han llenado una función psicológica esencial: absorber las sombras y ofrecer una tumba cotidiana a todo lo que, cada día, muere en nosotros" (p. 89). En ese sentido, Borges comprende dicho elemento como se comprendía desde la concepción más arcaica, es decir, el agua como símbolo de purificación, pero lo más interesante es que lo asimile al sueño en el sentido de que es ahí, precisamente en el sueño, que nos purificamos de todo lo vivido en el día, pero no solo eso, sino que retomamos fuerzas para continuar viviendo. Esto es reforzado por ideas como la propuesta por Mircea Eliade (1974) en las que se menciona que en el Mundo Antiguo:

La inmersión en el agua simboliza la regresión a lo preformal, la regeneración total, el volver a nacer, porque la inmersión equivale a una disolución de las formas, a una reintegración en el modo indiferenciado de la preexistencia; la salida de las aguas reproduce el gesto cosmogónico de la manifestación formal. El contacto con el agua implica siempre regeneración; de un lado, porque la disolución va siempre seguida de un «nuevo nacimiento»; de otro, porque la inmersión aumenta el potencial de vida. (p. 223)

En ese sentido, Borges solo podrá escapar de esa pesadilla en la medida en que logre limpiarse de aquello que lo afecta, de eso que, como dice "no se nombra y que lo alcanza desde ayeres del mito" y la única forma es bañándose en las aguas purificadoras del sueño, un verdadero sueño profundo. En ese sentido, en este poema, las aguas simbolizan un elemento purificador, aunque ese mismo elemento también puede ser peligroso, dependiendo de la forma en la que muestre; así, por ejemplo, las aguas mansas o serenas simbolizarán la tranquilidad, la protección. No obstante, las oscuras, turbulentas, bravas, representarán peligros, olvido, muerte, como se verá en el siguiente apartado.

\section{"Brunanburh" y "En memoria de An- gélica": el agua, la muerte y el olvido}

\section{Brunanburh}

Nadie a tu lado.

Anoche maté a un hombre en la batalla. Era animoso y alto, de la clara estirpe [de Anlaf.

La espada entró en el pecho, un poco a [la izquierda.

Rodó por tierra y fue una cosa, una cosa del cuervo.

En vano lo esperarás, mujer que no he [visto.

No lo traerán las naves que huyeron sobre el agua amarilla.

En la hora del alba, tu mano desde el sueño lo buscará. Tu lecho está frío.

Anoche maté a un hombre en

[Brunanburh.

(Borges, 1989, p. 101)

\section{En memoria de Angélica}

¡Cuántas posibles vidas se habrán ido en esta pobre y diminuta muerte, cuántas posibles vidas que la suerte daría a la memoria o al olvido! Cuando yo muera morirá un pasado; 
con esta flor un porvenir ha muerto en las aguas que ignoran, un abierto porvenir por los astros arrasado.

Yo, como ella, muero de infinitos destinos que el azar no me depara; busca mi sombra los gastados mitos de una patria que siempre dio la cara. Un breve mármol cuida su memoria; sobre nosotros crece, atroz, la historia.

(Borges, 1989, p. 108)

De las muertes más deshonrosas que se podrían considerar en la Antigüedad, está la producida en el mar; no porque se considerase dolorosa sino porque morir ahogado o en un naufragio impedía establecer un lugar en el que se pudiese rendir culto al muerto. "[...] el héroe, tal y como lo manifiestan Telémaco y Odiseo, tras su muer-

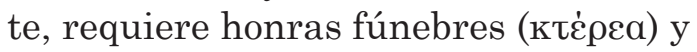

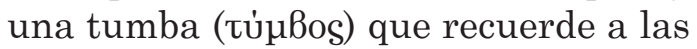
generaciones venideras su existencia" (González, 2010, p. 104).

En ese sentido, en los poemas antes citados, es clara la intención de mostrar al agua como símbolo del olvido pues, por ejemplo, en Brunanburh se menciona "en vano lo esperarás, mujer que no he visto. No lo traerán las naves que huyeron sobre el agua amarilla”. Acá se describe una Penélope que espera a su marido sin saber que ha muerto, pero lo impactante es que se ha ido en una embarcación, es decir, ha surcado el mar, al estilo de los héroes griegos, y no regresará porque ha sido asesinado en una región lejana. Ese mar, esas aguas amarillentas, cortadas por la quilla del barco representaron para esa mujer la despedida absoluta de su esposo y, en cierto modo, su muerte simbólica, pues el no regresar, el perderse en el mar (que así lo vería la mujer) es como esfumarse; un hecho quizá más doloroso que saber que su marido ha sido asesinado.

Unido a lo anterior, al igual que los antiguos griegos, al desaparecer en el mar, se le imposibilitará (a esa mujer que lo espera) realizar las honras fúnebres y, por lo tanto, se niega la posibilidad de que el hombre sea recordado por siempre. El no poseer un monumento (aquí hay que recordar la etimología de esta palabra, es decir, su relación con la memoria) funerario para que se le recuerde reduce la muerte a la condición del olvido y, con esto, a la desaparición del fallecido; en otras palabras, no se recordará nada de lo que pudo haber hecho mientras estuvo con vida.

Esas mismas aguas del olvido "ignoran un abierto porvenir" en "Memorias de Angélica". Con la muerte todo acaba: la suerte, el pasado, todo por lo que se trabajó, todo lo que se conoció, produjo y pensó; no obstante, en el caso de este poema, se presenta una diferencia en relación con el anterior y es que en el caso del receptor "un breve mármol cuida su memoria". En ese sentido, Bachelard (2003) menciona que "el agua [...] tiene a la muerte en su seno. El agua ofrece la muerte elemental. El agua muere con lo muerto en su sustancia. El agua es, entonces, una Nada sustancial. No se puede ir más lejos en la desesperación. Para ciertas almas, 'el agua es la materia de la desesperación”' (p. 49).

Pero apegado al tema de muerte, que es hacia donde avanzamos, el agua también simboliza el tiempo y su inquebrantable transcurrir, tal como se manifiesta en el poema "Heráclito", que comentaremos seguidamente. 
Heráclito: el agua y la continuidad del tiempo

Heráclito camina por la tarde De Éfeso. La tarde lo ha dejado, Sin que su voluntad lo decidiera, En la margen de un río silencioso Cuyo destino y cuyo nombre ignora. Hay un Jano de piedra y unos álamos Se mira en el espejo fugitivo Y descubre y trabaja la sentencia Que las generaciones de los hombres No dejarán caer. Su voz declara: Nadie baja dos veces a las aguas Del mismo río. Se detiene. Siente Con el asombro de un horror sagrado Que él también es un río y una fuga. Quiere recuperar esa mañana Y su noche y la víspera. No puede. Repite la sentencia. La ve impresa En futuros y claros caracteres En una de las páginas de Burnet. Heráclito no sabe griego. Jano, Dios de las puertas, es un dios latino. Heráclito no tiene ayer ni ahora. Es un mero artificio que ha soñado Un hombre gris a orillas del Red Cedar, Un hombre que entreteje endecasílabos Para no pensar tanto en Buenos Aires $\mathrm{Y}$ en los rostros queridos. Uno falta.

(Borges, 1989, p. 156)

"Nadie baja dos veces a las aguas del mismo río" (p.156). Con esta clara referencia al agua y a la cambiante vida del ser humano, Jorge Luis Borges presenta su poema "Heráclito".

$\mathrm{El}$ intertexto, tomado del filósofo griego, es explícito en tanto pretende demostrar que la vida es como el agua del río que cambia constantemente, pero que no se detiene nunca; fluye como tiempo y que, por ello, lo visto en un determinado instante no podrá volverse a ver.
Frente a esta 'pérdida' constante y gradual de la vida del ser humano en esas aguas que simbolizan el tiempo, Borges nos insta a encontrar un espejo que nos permita ver los cambios que sufren nuestros cuerpos y ese espejo será el mismo de Narciso: el agua, pues esta posibilita el reflejo del universo, tal como lo muestra también en el poema "Al espejo" cuando menciona que "en la tersura del agua incierta o del cristal que dura/me buscas y es inútil estar ciego" (Borges, 1989, p. 109). Esa agua es la fuerza que se presenta como el cimiento de los porvenires, de la vida misma, pues es tiempo (apoyado en las palabras de Heráclito), es sucesivo, fluye como un río y no se detiene.

Esta idea del agua como símbolo del tiempo es retomada por Borges en un ensayo suyo, al mencionar que:

El tiempo es la sucesión [...] No sé si al cabo de veinte o treinta siglos de meditación hemos avanzado mucho en el problema del tiempo. Yo diría que siempre sentimos esa antigua perplejidad, esa que sintió mortalmente Heráclito en aquel ejemplo al que vuelvo siempre: nadie baja dos veces al mismo río. ¿Por qué nadie baja dos veces al mismo río? En primer término, porque las aguas del río fluyen como fluye el tiempo. En segundo término, esto es algo que ya nos toca metafísicamente, que nos da como un principio de horror sagrado, porque nosotros mismos somos también un río, nosotros también somos fluctuantes. (Borges, 1998, p. 70)

De esa manera, si el agua en ese río es tiempo, es contraste, es cambio y los seres humanos compartimos esa característica 
mutabilidad, será imposible no volverse uno con estos, tal como lo señala en su "Arte poética", poema que aparece en el poemario El hacedor:

Mirar el río hecho de tiempo y agua y recordar que el tiempo es otro río, saber que nos perdemos como el río y que los rostros pasan como el agua.

(Borges, 1989, p. 177)

El tiempo devela el cambio y la permanencia a partir de este "gran texto", "el texto universal", conquista la eternidad y adquiere una condición revelatoria. En estos versos, el tiempo es agua y es río, un río que sigue su curso, porque "los rostros pasan como el agua", todo transcurre de la mano del tiempo. El poema formula una afirmación sencilla, la condición de permanencia y de inmortalidad de la poesía, condición que es a la vez temporalidad e intemporalidad.

Esas aguas que simbolizan el tiempo, las aguas del río de Heráclito, recuerdan al ser humano lo efímera que es su existencia y cómo, al igual que fluyen las aguas, la vida cada día fluye hacia un mar que es el fin, tal como dicen aquellos versos de Jorge Manrique (1983): "Nuestras vidas son los ríos que van a dar a la mar que es el morir" (p. 48).

\section{Conclusiones}

La polivalencia de las imágenes, los mitos y los símbolos, mediante la revalorización del imaginario, permite revelar los más profundos significados que posee el agua en los poemas "Proteo", "Brunanburh", "En memoria de Angélica", "Al espejo", "Efialtes", publicados en el poemario titulado La rosa profunda (1975) y "Heráclito", publicado en el poemario titulado La Moneda de Hierro (1976).

Jorge Luis Borges, a partir de su amplio conocimiento del Mundo Clásico, atribuye al agua una serie de significaciones que le permiten asociarla simbólicamente a conceptos como el olvido, la muerte, los sueños, el tiempo y lo efímero de la vida.

La asociación de las aguas del río con el tiempo es recurrente, por la referencia al intertexto de Heráclito o porque el tiempo es una abstracción; en otras palabras, no tiene existencia como tal, sino que se construye metafísicamente en el sentido de que en él se conjunta lo inexorable, lo venidero y lo desconocido.

Finalmente, el agua se reviste, en los poemas borgianos de tema clásico estudiados en este trabajo, de una significación que la convierte en un símbolo versátil, plurivalente, que encierra la movilidad propia de su condición líquida. Hecho que, sin duda, la ha convertido en un símbolo de transformación y, como tal, se ha fijado en el imaginario occidental.

\section{Notas}

1. Texto original: "C'est l'interaction des différentes instances de la psyché, le lieu informel, dialectique, dialogique, du "discours" complexe entre les couples antagonistes et complémentaires ordre/ désordre, rationnel/irrationnel, homogène/hétérogène, rigide/souple, etc... C'est notre façon de nous penser vivants. Et ces interactions determinant une tension organisatrice des différentes instances de la psyché, qui est en même temps le moteur de son évolution". 


\section{Bibliografía}

Bachelar, G. (2003). El agua y los sueños: ensayo sobre la imaginación de la materia. Fondo de Cultura Económica.

Bauzá, H. (2004). El imaginario en el mito clásico. El imaginario y las formas rituales. Academia Nacional de Ciencias de Buenos Aires. (2007). En torno a l'imaginaire: Entrevista al filósofo del imaginarie Jean-Jacques Wunenburger. Revista Annos 90, Vol.14, pág. 220.

Borges, J. (1989). Obras completas. Tomo II. EMECÉ. (1998) "El tiempo" en Borges oral. Alianza.

Durand, G. (1968). La imaginación simbólica. Amorrortu Editores. (2004). Las estructuras antropológicas del imaginario. Fondo de Cultura Económica. (1993). De la mitocrítica hacia el mitoanálisis. Figuras míticas y aspectos de la obra. Introducción, traducción y notas de Alain Verjat. Anthropos. (2000). Lo imaginario. Ediciones del Bronce.
Eliade, M. (1974). Tratado de historia de las religiones. Cristiandad. (1989). Imágenes y símbolos. Ensayos sobre el simbolismo mágico-religioso. Trad. Carmen Castro. Taurus.

González, G. (2010). Una aproximación crítica a los sentidos de la muerte en la literatura griega arcaica. (Tesis inédita para optar por el grado de maestría). Universidad de Costa Rica. San José, Costa Rica.

Homero. Odisea. Gredos.

Jung, C. G. (2011). Símbolos de transformación. Paidós.

Lotman, I. M. (2002). El símbolo en el sistema de la cultura. Forma y función, (15), pp. 89-101.

Manrique, J. (1983). Coplas a la muerte de su padre. Castalia.

Ricoeur, P. (2004). La simbólica del mal, en Finitud y Culpabilidad. Editorial Trotta.

Thomas, J. (1992). Les imaginaires des latins. Actes du colloque international de Perpignan. Presses Universitaires de Perpignan. 
